\title{
Newly-qualified social workers: A practice guide to the Assessed and Supported Year in Employment (3rd ed.)
}

Steven Keen, Jonathan Parker, Keith Brown, and Di Galpin (Eds.), 2016 SAGE Publications, London, UK ISBN: 978-4739-7797-6, pp. 233, paperback, NZD47.05

$\mathrm{T}$ his practice guide has been written to assist newly qualified social workers (NQSWs) in their first year of employment. The specific focus is for NQSWs in the UK, where there is a requirement to meet specific knowledge and skills competencies in the structured Assessed and Supported Year in Employment (ASYE). The obvious limitation of this practice guide for an international readership is this specific focus on UK social work and legal processes. However, there are some helpful sections that can apply to any new social worker.

The practice guide is an edited book with chapters including the transition from student to social worker, critical reflection and continuing professional development (CPD), supervision, induction, self-care, team-work and service development. There are appendices with practical advice about using written skills, court skills, child protection, and safeguarding adults. The guide was developed as a result of research findings from tracking NQSWs in the UK. It was originally published in 2009 and has been updated twice since then in response to updated legislation. Each chapter is well structured, with clear signalling of the relevance to the ASYE professional capabilities, knowledge and skills. Each chapter concludes with signposting to further reading and a summary of the key points. Chapters include case studies, self-reflection activities, and relevant figures and tables illustrating theoretical concepts.
A distinguishing feature is the range of contributors, including service users, carers, managers, academics and NQSWs. Vignettes that include the voice of service users and carers are poignant, helping to link theory to practice, and serve as reminders of the importance of effective social work. The practice guide has been written in such a way that readers can dip into areas of interest as needed. It covers a broad range of areas, and readers are encouraged to follow further reading suggestions to gain a depth of understanding on specific topics.

After getting through the chapter about the ASYE process, which has no relevance to social workers outside of the UK, there were some gems to be found. From my experience working alongside new graduate social workers in Aotearoa, there were several topics that are relevant to NQSWs, as well as good reminders and reflection for more experienced social workers.

The chapter by Steven Keen, Lynne Rutter, Keith Brown and Di Galpin, with contributions from Angela (NQSW) and Jane (social worker) about CPD and critical reflection provides a good overview of the purpose of CPD. They encourage social workers to take ownership of CPD, and to identify what learning is required to meet personal and professional goals. They explain the CPD cycle by Brown, Rutter, Keen, and Rosenorn-Lanng (2012), as well as Rutter and Brown's (2015) elements and activities of critical expert practice, dimensions of critical reflection, and 
framework of practical reasoning principles. This is then linked to a reflective exercise, asking the reader where they want to be in five years, and the skills required for this. The chapter does rely on a CPD case study from a social worker who completed a post-qualifying Masters degree. Given the relative rarity of additional postgraduate education for social workers in Aotearoa, there is scope for further CPD examples that are more applicable to international readers. CPD discussion is relevant for all readers, but particularly for social workers in Aotearoa, with the SWRB requirement of up-to-date CPD logs available for audit. This chapter provides some useful guidance about how social workers can use CPD in a meaningful way aligned to learning goals and professional ambitions.

Managing transitions is addressed in the chapter by Lee-Ann Fenge with contributions from Mark Hutton (manager), Tom (NQSW) and Tom's university tutors. After moving beyond the UK-centric tips for how to search for social work jobs on UK websites, there are nuggets of gold for job-seeking NQSWs. From my own experience interviewing new graduates for social work positions, I wish that this information was available to all candidates. There are excellent practical suggestions for how to approach job applications, including ensuring no gaps in employment history, how to choose referees, CV formatting, and tips to be best prepared for an interview. Tom's case study provides excellent guidance for how to do this well. There is also discussion about the psychological transition from student to social worker, paying particular attention to the loss of a class of peers, which may often be overlooked by eager new social workers.
Ivan Gray, with contributions from Mary (NQSW) and Karen (carer), wrote the chapter on managing induction, probation and supervision. Again, there is a theme of NQSWs taking ownership of their role in ensuring helpful induction and supervision, in partnership with other team members, managers and supervisors. Of concern is a case study about Mary's first job, where she often starts early and finishes late. This appears to have been portrayed as a good example for a NQSW. While this may be the reality for many NQSWs, it does not seem helpful to have this presented as an exemplar. The subsequent chapter about thriving in social work, written by Kate Howe, with contribution from Pru CaldwellMcGee (NQSW), is a lovely antidote for such pressures. There is excellent discussion about stress, sphere of influence and control, and self-management.

While this guide book is written specifically for NQSWs in the UK, with whole sections that are irrelevant for other readers, there is value to be found. Professional and selfdevelopment for NQSWs is important, and our new social workers should be supported as they transition into the workplace. There is a role for all of us in this work, in order to support and retain social workers with upto-date research knowledge and fresh-eyed enthusiasm for social work.

\section{References}

Brown, K., Rutter, L., Keen, S., \& Rosenorn-Lanng, E. (2012). Partnerships, CPD and APL. Birmingham, UK: Learn to Care.

Rutter, L., \& Brown, K. (2015). Critical thinking and professional judgement in social work (4th ed.). London, UK: Sage/Learning Matters.
} 